Journal of Research in Interprofessional

Practice and

Education

Vol. 7.1

2017

a. University of California,

San Diego;

b. University of San Diego;

c. Rady Children's

Hospital,

San Diego;

d. Kaiser

Permanente

\title{
An Autoethnographic Study of Interprofessional Education Partnerships Authors
}

\author{
Samantha Hurst, PhD, M.A. ${ }^{a}$; Karen A. Macauley, PhD, DNP, APRN ${ }^{\text {; }}$; \\ Linda Awdishu, Pharm.D, MAS ${ }^{a}$; Kathleen M. Sweeney, DNP, CPNP-PC ${ }^{c}$; \\ Sophie S. Hutchins, DNP, CHSE ${ }^{b}$ Jennifer M. Namba, Pharm.D, BCP ${ }^{a}$; \\ Michelle L. Johnson, $\mathbf{M D}^{\mathrm{a}}$; Peggy A. Wallace, $\mathrm{PhD}^{\mathrm{a}}$; \\ Karen A. Garman, EdD, PCCd; Amy M. Zheng, MD, M.Phila
}

\begin{abstract}
Background: This qualitative longitudinal study describes an Interprofessional Education (IPE) collaboration between a public university with medical and pharmacy schools and a private, non-affiliated university with a nursing school. The study explores the dynamics of the IPE partnership and lessons learned over a threeyear period in which members of the collaborative directed three IPE simulations.

Methods and Findings: An autoethnographic inquiry technique was used to interview eight collaborators who designed and implemented a large-scale IPE simulation for approximately 300 students and 100 faculty members annually for three years. Two, 90-minute group narrative interviews were conducted and audio recorded for transcription and analysis. Five themes emerged: Natural Collaboration, Shared Vision and Commitment, Integrations and Synergy, All Hands on Deck, and Lasting Foundations. Collaborators agreed the joint effort was a positive experience with multidimensional returns on investment. They applied teamwork competencies to build the partnership, develop the IPE simulation, and overcome implementation challenges.

Conclusions: This article provides readers with the opportunity to learn from those who have been intimately involved in the design and implementation of a large-scale IPE collaboration to enhance the shared learning process for health students and faculty. Findings highlight the complexity of building an IPE collaborative and the necessity to build partnerships with facilitators committed to communication and cooperation between academic, community, and service institutions.
\end{abstract}

Keywords: Interprofessional education; Simulation; Faculty development; Autoethnography

Journal of Research in Interprofessional Practice and Education (JRIPE)

Vol. 7.1

(c) 2017

Corresponding author: Karen A Macauley. Email: macauley@sandiego.edu

\section{Introduction}

The Joint Commission on Accreditation of Healthcare reports that " $70 \%$ of preventable medical errors are due to communication errors" [1, p. 872]. Interprofessional teamwork experiences should occur early in medical training before learners become engrained in their discipline-specific ideals and tainted by established hier- 
Interprofessional Education Partnership

Hurst, Macauley, Awdishu, Sweeney, Hutchins, Namba, Johnson, Wallace, Garman, \& Zheng

Journal of Research in Interprofessional Practice and Education archies and preconceptions [2]. The Institute of Medicine (IOM), World Health Organization (WHO), and Interprofessional Education Collaborative (IPEC) support a convergence of collaborative practice to improve health outcomes and interactive interprofessional educational (IPE) methods. While most accreditation agencies and reports promote IPE, the ability to operationalize IPE into academic institutions is daunting and challenging.

The spectrum of IPE ranges from shared curricula, team-based learning in small groups, and simulation-based activities to experiential clinical training. Simulation is increasingly being used as a method to foster interprofessional experiential learning across healthcare disciplines. Recent studies have shown that IPE simulation education "can be effective in promoting knowledge, skills, and attitudes that may prepare learners for effective interprofessional collaborative practice” [3, p. 13].

This qualitative longitudinal study describes an IPE collaboration between a public university with medical and pharmacy schools that are affiliated with an academic health system, and a private non-affiliated university with a nursing school. Using an autoethnographic approach [4], IPE collaborators describe their experience over a three-year period, from creating the foundational steps to maintaining the sustainability of three large-scale IPE simulations. The development and coordination of conducting simulations united these three professional institutions, which had no prior collaborative endeavours [5-7]. Each simulation activity involved approximately 300 pre-clinical medical, pharmacy, and pre-licensure nursing students, and 100 interprofessional facilitators, lasting over two half-days. The simulation exercises took place in multiple patient-care settings requiring the application of discipline-specific skills and handoff communication at the transitions of care.

\section{Methods}

\section{Research design}

The use of autoethnography as a qualitative inquiry technique allows researchers to contribute as storytellers and share insights into their own research and learning experiences $[4,8]$. In the current study, autoethnography is employed to gain a reflexive understanding from eight collaborators who partnered together as designers and facilitators for the IPE simulation. Two group narrative interviews were conducted in June 2013 and June 2015. All eight of the IPE collaborators from nursing, pharmacy, medicine, and medical education participated in the first interview, while seven participated in the second interview (one member accepted a position at another institution). The serial group interviews permitted a longitudinal perspective initiated by developing relationships within an IPE collaborative, as well as exploring the resulting preparation needed and practice events of the separate IPE simulations for healthcare students.

\section{Data collection}

A qualitative medical anthropologist facilitated two semi-structured group interviews by presenting a set of general questions that could be answered and respon- 
Interprofessional Education Partnership

Hurst, Macauley, Awdishu, Sweeney, Hutchins, Namba, Johnson, Wallace, Garman, \& Zheng

Journal of Research in Interprofessional Practice and Education

\section{Journal of Research in Interprofessional Practice and Education}

sively adapted to the role of each IPE collaborator to gain an interdisciplinary perspective of the IPE simulations (see Appendix A). Support documents related to the development of the collaborative (e.g., initial collaboration meeting notes, and faculty and student learner guides) were used to inform the framework for the interview questions. The interview sessions lasted approximately 90 minutes and were digitally recorded so that transcripts could be produced for narrative analysis. Verbal informed consent was established with each interviewee prior to the start of the interviews and also by electing to participate. A contracted transcriptionist finished transcribing the interviews in late September 2013 and 2015. This study was conducted with Institutional Review Board approval from both universities.

\section{Qualitative data analysis}

The analysis of the autoethnographic data was influenced by the three-dimensional space approach of D. Jean Clandinin and F. Michael Connelly [9], in which the stories revealed within the two group discussions were analyzed for elements of interaction (personal and partnership), continuity (past and present), and situational context (practice of simulation activities). The resulting analytic schema helped to illuminate the nuanced process of integration within and across all collaborators' stories. Reading the transcripts thus involved searching for similarities and different perspectives by making systematic comparisons for each response across all of the questions and examining how any one response might be different from or analogous to the other [10]. The analysis of the transcripts was conducted manually by the medical anthropologist using Microsoft Word and the comment tool in the "review" mode to highlight and tag noteworthy segments of text responding to the objective of each question [11]. At the conclusion of the analysis, the results were shared with IPE collaborators to review for accuracy and the confirmation of relevant details in the IPE partnership. IPE collaborators also contributed to the final editing of the manuscript to further verify that the reflexivity and voice of their experiences was authentically captured in this article.

\section{Results}

The presentation of findings includes five thematic areas bridging both interviews. Within each of the themes, quotes are presented that best highlight and describe illustrative comments offered by the IPE collaborators to demonstrate their process of growth and transformation:

1. Natural Collaboration;

2. Shared Vision and Commitment;

3. Integrations and Synergy;

4. All Hands on Deck; and

5. Lasting Foundations.

\section{Natural collaboration}

All interviewees cited their primary motivation for establishing an interprofessional collaboration as changing health education from a "discipline" to a "team-focused" 
Interprofessional Education Partnership

Hurst, Macauley, Awdishu, Sweeney, Hutchins, Namba, Johnson, Wallace, Garman, \& Zheng

Journal of Research in Interprofessional Practice and Education approach. It was noted that while discipline-specific motivations were different for IPE, the overall goals of the collaboration could be aligned without undermining discipline needs, and in fact prove to enhance the outcomes of the partnership. Many of the interviewees referred to the natural collaboration that evolved from initial opportunities for faculty to meet and talk with one another about individual program needs.

Our nursing school was implementing a standardized patient program and reached out to the school of medicine for guidance since they were in our own backyard. We invited them to a meeting with our regional simulation collaborative and discussed how great it would be to work together ... instead of doing simulations only in our own institution. We were looking for opportunities to involve medical students. (Nursing, 2013)

The opportunity came to do something for medical students during the transition from second to third year. I wanted the students to be energized to make them excited about clinical rotations. I thought wow, an IPE simulation would be a really nice thing to do and then I started talking to pharmacy and nursing, and it all just kind of came together. (Medicine, 2013)

Prior to the IPE development, collaborators acknowledged the lack of inter-discipline engagement in their respective simulation activities. Simulation experiences ranged from no activities (pharmacy) to established standardized patient programs (medicine/nursing), some of which had developed clinical case scenarios using standardized patients to improve communication training in the simulations. Thus, the standardized patient methodology became the common ground for building the collaborative IPE simulations.

I was only doing mannequin-based simulation and I realized the communication piece was just missing. We worked with medical school and ended up getting standardized patients ... and that brought in the communication piece, but some of the cases I was doing required a lot of medications. We were kind of hand waving make-believe meds ... so we invited the pharmacy school to participate in our sims with their residents. (Medicine, 2013)

Especially in healthcare education, it's all about caring. How can you learn or demonstrate care for a patient if you can't practice that? So I think that that piece of it is very powerful and it's bedside manner, it's reflective practice, it has to go back to all of those basics of listening, how well of a listener are you as a team not only as a professional, as an individual ... it's about quality and how we do it and putting this much time and energy is what's really needed to get good scenarios. (Nursing, 2015)

External factors also presented an impetus toward natural collaboration. Accreditation standards and grants funded by the National Institute of Health 
Interprofessional Education Partnership

Hurst, Macauley, Awdishu, Sweeney, Hutchins, Namba, Johnson, Wallace, Garman, \& Zheng

Journal of Research in Interprofessional Practice and Education

\section{Journal of Research in Interprofessional Practice and Education}

(NIH) and the National Center of Leadership in Academic Medicine (NCLAM) outlined principles and resources for developing IPEs. Specifically, the NIH grant addressed objectives outlined within the IOM report.

I have to also consider all the accreditation firms that are looking at our school of nursing that are now requiring interprofessional education. So for us to be certified through CCNE [Commission on Collegiate Nursing Education] or AACN [American Association of Colleges of Nursing], through all these different colleges of nursing, they really want to see a push in interprofessional education. (Nursing, 2013)

I was invited to collaborate on an NIH grant to develop IPE with the school of medicine. The NIH grant not only provide funding and protected time to develop IPE, but also redefined the partnerships between our two schools. (Pharmacy, 2015)

\section{Shared vision and commitment}

The collaborators repeatedly described their strong motivation and commitment for developing IPE simulations. This shared vision was central to forming an integrated team, as well as a framework for the highly functioning collaborative.

The thing for me in the beginning was the fact that we all had the same vision and none of us had ever seen anything like it. We had 285 novice learners and 88 faculty who put their trust in us ... the trust that we could actually take it to the level we did. (Medical Education, 2013)

I think if you look at the scale of what we did ... to think that it could be accomplished by how many of us only speaks to our commitment and cooperation. Typically, you think you need 20 people to do this. I remember someone asking me, "How many people were on this planning committee?” And I said, “About 8?” (Nursing, 2015)

Several collaborators also acknowledged logistical challenges and personal apprehensions about the commitment to implement such a large-scale project. As relationships developed, the interviewees acknowledged the strengths of each member, which encouraged confidence in moving forward with the shared vision. Mutual respect among disciplines and individual contributions overcame apprehensions about successful execution.

I think at the beginning not knowing how something this huge would take off ... the nervousness within ourselves to focus and to make sure that we had the right leaders and that each of us had a specific part. The discussion between us early on when we didn't know each other ... we didn't want to hurt each other's feelings so we were a little more reserved and didn't want to argue. (Nursing, 2015) 
Interprofessional Education Partnership

Hurst, Macauley, Awdishu, Sweeney, Hutchins, Namba, Johnson, Wallace, Garman, \& Zheng

Journal of Research in Interprofessional Practice and Education

\section{Journal of Research in Interprofessional Practice and Education}

Interprofessional education learning objectives for students also evolved over time. In the beginning, collaborators created a discipline-specific, task-oriented checklist to assist simulation facilitators in their observations of student groups (medical, nursing, or pharmacy) as they completed simulation tasks.

I think the thing that stuck out in the first year of doing this was I felt very uncomfortable with the checklists. And I felt uncomfortable with faculty development because I just wasn't familiar with it. And now I know that discomfort was appropriate. And that not many other people know how to do this very well. And that the field is growing and that we really do have people on the team that are at the top of the field and are helping to kind of define faculty development, that are helping to measure IPE outcomes. There isn't a cookie cutter approach. (Pharmacy, 2015)

With each successive year, simulation facilitators relied less on task-based checklists and emphasized more team-engaged competencies as specific aims. Collaborators suggest this change demonstrates a greater sense of familiarity over time with IPE competencies.

\section{Integration and synergy}

Equally important to the enhancement and learning of IPE competencies was the confidence among collaborators that each team member understood the value of working synergistically.

So the thing that has always struck me even from day one was the integration of teamwork that we've always displayed. And my thought has always been that if you're going to teach teamwork you should be able to role model it. And it's always struck me that we show mutual support, trust, situational monitoring by saying, "Okay, you've got too much on your plate. This is something I can do. Let me work on it." (Medicine, 2015)

There was always somebody who would come up with a solution ... there was never any "Oh I've already done so much, I can't do anymore." People were willing. There was very little red tape within our group, which is refreshing for a committee. (Pharmacy, 2013)

While IPE collaborative identity did not replace professional role identity, the partnership members became more fluent in their abilities to support the needs of each of the disciplines involved.

We really liked each other ... we were honouring each other's expertise ... really honouring it, not fake honouring it and that's what happened with the students. They realized too what pharmacy can bring. They know what nurses do. And for me that's where the heart of it is. (Medical Education, 2013) 
Interprofessional Education Partnership

Hurst, Macauley, Awdishu, Sweeney, Hutchins, Namba, Johnson, Wallace, Garman, \& Zheng

Journal of Research in Interprofessional Practice and Education

\section{Journal of Research in Interprofessional Practice and Education}

Remember we are all caretakers. If you think of it that way ... we want to take care of each other besides take care of the patients and the students. So I think a lot has to do with our success as a team, we are all are in caring professions. (Nursing, 2015)

\section{All hands on deck}

Collaborators attributed the overall success of the IPE simulations to building a strong infrastructure, which included the opportunity for additional faculty and staff to facilitate the event. The large scope of the activity required participation from volunteer facilitators and staff to be successful. Interviewees noted that support from leadership and stakeholders from all schools was available and essential both for the initial and continued execution of the event.

The coordination of students and faculty was amazing ... I've never seen such a collection of bodies working simultaneously like this ... it was amazing. We had more hands on deck, including leadership and staff support, than we probably needed but it was incredible that they were all there and as dedicated as we were. (Medical Education, 2013)

During the first year we ran the simulation, one of the admins from the nursing school just started coming to the meetings and finding solutions ... such as printing name badges for all three schools ... and ... colour coding everything according to each of the schools... she just wanted to be of help. (Pharmacy, 2015)

The IPE simulations also became a community-building event. Clinicians and educators from the community offered their time as volunteer facilitators.

In the beginning, we had to heavily recruit for facilitators. Later, our service partners and other nursing schools reached out to us to participate as facilitators because of the excitement surrounding this regional event. (Nursing, 2015)

\section{Lasting foundation}

Many collaborators described the enthusiasm and reciprocation of learning that was observed throughout the entire development of the IPE simulations. The IPE brought training experiences closer to practice than ever before for their students. Many collaborators acknowledged the impact of IPE student experiences and the positive engagement that was established within the student teams.

I was incredibly proud and I am incredibly happy to have been a part of this. That has been the theme for me, it's been a wonderful culmination of teamwork ... there were also a couple really proud moments that were monumental to my career, like when I saw students coming out of the debriefings, hugging each other and giving each other their phone number. (Pharmacy, 2013) 
Interprofessional Education Partnership

Hurst, Macauley, Awdishu, Sweeney, Hutchins, Namba, Johnson, Wallace, Garman, \& Zheng

Journal of Research in Interprofessional Practice and Education

\section{Journal of Research in Interprofessional Practice and Education}

I remember I sat in on a debriefing, it was the media group. One of the students ... one of the medical students said ... "Now that I know what a nurse and pharmacist can do, I'm going to clutch them to my breast and never let them go." I thought YES ... YES ... this is why we did it. (Medicine, 2013)

When specifically asked about the greatest return of investment for all the time and energy dedicated to the three-year collaboration, every IPE member identified benefits provided to their respective students.

I think it's the students, their excitement about training together ... because they may not see it at the attending level around them every day, but I see it in the hospital ... the pharmacy students are talking with the medical students ... Even though we have a joint curriculum, I think events like this is where they have really gotten to know each other. (Pharmacy, 2015)

I think what really cinched it for me was observing the medical school debriefing. There were multiple times when the students said something to the effect of, "I don't know very much but now I know I'm not alone." And I thought that is why we do it. So I'm hoping that as we get them when they're young, that they can go forth and grow and mature a little more and then make the changes. (Medicine, 2015)

Many of the collaborators described how the IPE experience personally opened a new chapter in health profession education and academic scholarship in their careers.

The continued dissemination of our work has been an unexpected reward that we didn't anticipate starting out. The opportunity to present internationally, publish, and be recognized by AHRQ [Agency for Healthcare Research and Quality] as an exemplar of TeamSTEPPS $^{\circ}$ has been phenomenal for all of our careers, personally and professionally. (Nursing, 2015)

Some of the interviewees pointed out the subsequent effect of the IPE simulation in their respective school curriculum:

It's influenced the curriculum in pharmacy tremendously. I mean we're trying to create a whole formal course in professional practice, incorporating communication training, skills development, and simulations. (Pharmacy, 2015)

By the third year, the IPE team acknowledged challenges in maintaining the same level of commitment to the partnership. The collaborators expressed different views on whether to use their time to write a new case scenario or continue using the same one. The group has become instrumental in providing ways to problemsolve and develop solutions for disagreements. 
Interprofessional Education Partnership

Hurst, Macauley, Awdishu, Sweeney, Hutchins, Namba, Johnson, Wallace, Garman, \& Zheng

Journal of Research in Interprofessional Practice and Education

\section{Journal of Research in Interprofessional Practice and Education}

As our IPE has grown, people's plates have gotten fuller, publications, grants. And so how do you get together and make a new case? But the nice thing about this group is that we just talk about things. And we all sat together and talked it through and it was a lot easier than in the beginning to simply say I don't think that's going to work. So we decided to create a new case because we realized we had the logistics down. (Medicine, 2015)

Some of the interviewees identified the need for more resources and institutional support to advance the IPE mission long term.

In future years, it would be very helpful to have more institutional support. We've had students every year who say, "I would love to do this multiple times a year." I just can't imagine having that kind of time to dedicate to it without institutional support. I think it would be great to have an IPE director or program that is inter-institutional. Let's bring in all of these different people and have resource sharing, and have an integrated curriculum. (Medicine, 2015)

\section{Discussion}

Five themes emerged from the series of autoethnographic interviews with collaborators who partnered together to develop and implement large-scale IPE simulations. Collaborators overwhelmingly agreed that the joint effort was a positive experience, personally and professionally. By comparison, Jan Fook, Lynda D’Avray, Caroline Norrie, Maria Psoinos, Byony Lamb, and Fiona Ross [12] conducted a similar study in 2012 and found the development of IPE in their institution created conflict and discontent among collaborators due to divergent views regarding the purpose of IPE, inequitable resources, and disagreements over the methodology used to teach IPE. Similar to the study conducted by Fook et al. [12], our collaborators noted different skill sets and resources within the membership, but instead focused on enhancing individual strengths toward a shared vision that the experience should be learnercentric. The successful use of the simulation in promoting interprofessional education has been reported [13,14]. In contrast, Fook et al.'s [12] group did not consider simulation an alternative teaching tool. The current study endorsed the need for focused attention on students, the importance of simulation methods, and the value of resource sharing to build a platform for solid commitment and cohesion.

The second theme emerging from the collaborator interviews championed the utility of teamwork competencies in building partnership and developing the IPE simulation. While multiple frameworks for IPE core competencies and teamwork competencies exist, many of the individual domains are notably similar [7,15,16]. Diane E. MacKenzie, Shelley Doucet, Susan Nasser, Anne L. Godden-Webster, Cynthia Andrews, and George Kephart [17] reported on the importance of interprofessional program designers to practice and reflect on the same competencies that are expected of students. Shauna M. Buring, Alok Bhushan, Gayle Brazeau, Susan Conway, Laura Hansen, and Sarah Westberg [18] noted that faculty in IPE programs serve as important role models 
10

Interprofessional Education

Partnership

Hurst, Macauley, Awdishu, Sweeney, Hutchins, Namba, Johnson, Wallace, Garman, \& Zheng

Journal of Research in Interprofessional Practice and Education

Vol. 7.1

2017 for the students in their class. Collaborators also discussed specific ways in which their partnership demonstrated various aspects of IPE core competencies. For example, the group used the TeamSTEPPS ${ }^{\circledast}$ tool to teach students the critical elements of engaged teamwork prior to the IPE simulation. The use of this tool may have additionally allowed collaborators to practice and strengthen their understanding of teamwork, leading to greater cooperation in partnership. Similarly many of the collaborators were clinicians who also practiced in advanced, complex healthcare teams (emergency department, renal, primary care, and pediatric clinics).

While the IPE collaborators related strong commitment to the partnership, the collaboration was not without challenges. Challenges of IPE implementation have been well discussed in the literature $[19,20]$. Collaborators noted instances of apprehension and disagreements, such as whether the checklist should be on team- or task-based competencies and whether time should be spent developing a second case or writing publications, which may gain more academic recognition. However, this study showed that over time, collaborators became more comfortable voicing individual concerns and compromising to fulfill each discipline's needs. Collaborators also acknowledged the importance of administrative institutional resources for the sustainability of simulation events, although currently the partnership is limited in expanding IPE activities due to a lack of further support.

The return on investment for the collaborators was multidimensional. Everyone agreed that it was personally gratifying to see close to 300 students practicing teamwork at the simulated bedside. The IPE simulation unexpectedly served as a regional building event as community clinicians and educators participated as facilitators and were inspired to implement similar activities in their own institutions. For example, the pharmacy school used the IPE as a springboard to develop a simulation activity for its program. Moreover, the collaborative expanded its projects to publications and academic scholarship in IPE. This unanticipated benefit of the IPE partnership has been noted as a strategy to overcome some of the organizational barriers for faculty promotion [20].

This study employed a unique approach using serial interviews to assess longitudinal changes in new team collaboration over a three-year period. Fook et al. [12] assessed the dynamics of an established team that collaborated on IPE for 15 years in a single interview. Whereas the study demonstrated positive findings from the "honeymoon" period of new relationships, the Fook study revealed obstacles that evolved with long-term collaborations.

Another unique methodological aspect of this study is using autoethnography. Autoethnography has recently become a very popular qualitative research strategy that allows for a highly personalized style of drawing upon the experiences, goals, and attitudes of researchers and collaborators to create a helpful expository for new insights and practices in teaching and learning environments [21]. Within medical education, the practice of autoethnography provides a useful framework for IPE collaborators to examine the impact of novel teaching scenarios and to evaluate interdisciplinary partnerships for academic and student professional development [21]. 
Interprofessional Education Partnership

\section{Hurst, Macauley,}

Awdishu, Sweeney,

Hutchins, Namba,

Johnson, Wallace,

Garman, \& Zheng

Journal of Research in Interprofessional Practice and Education

Vol. 7.1

2017

\section{Limitations of the study}

The group interview versus an individual one-on-one interview format may have influenced the content and candor of discussion. However, collaborators did not believe the group interview format restricted their responses. Second, given the use of a qualitative framework, and the fact that all of the collaborators were of the same gender, with only three professions represented, the generalizability of the findings may be limited. The professions represented in this study work closely together in a clinical setting, which may account for the natural development of collaboration that was exhibited. Future research may evaluate whether this type of collaboration translates easily to community institutions by exploring how and if they were successful in developing a partnership to implement IPE.

\section{Conclusions}

This article provides readers with the opportunity to learn from those who have been intimately involved in the design and implementation of a large-scale IPE collaboration to enhance the shared learning process for health students and faculty. The interview findings highlight the complexity of building an IPE collaborative and the necessity to build partnerships with facilitators who are committed to communication and cooperation between academic, community, and service institutions.

\section{References}

1. Liston, B.W., Fischer, M.A., Way, D.P., Torre, D., \& Papp, K.K. (2011). Interprofessional education in the internal medicine clerkship: Results from a national survey. Academic Medicine: Journal of the Association of American Medical Colleges, 86(7), 872-876. doi:10.1097 /ACM.0b013e31821d699b

2. Barr, H. (2000). Working together to learn together: Learning together to work together. Journal of Interprofessional Care, 14(2), 177-179. doi:10.1080/jic.14.2.177.179

3. Murdoch, N.L., Bottorff, J.L., \& McCullough, D. (2013). Simulation education approaches to enhance collaborative healthcare: A best practices review. International Journal of Nursing Education Scholarship, 10(1), 307-321. doi:10.1515/ijnes-2013-0027

4. Adams, T.E., Holman-Jones, S., \& Ellis, C. (2014). Autoethnography. Oxford, UK: Oxford University Press.

5. Zheng, A., Macauley, K., Namba, J., Hutchins, S., Sweeney, K., Wallace, P., Garman, K., \& Awdishu, L. (2015). A large scale interprofessional simulation experience for medical, nursing, and pharmacy students. MedEdPORTAL Publications, 11, 10018. doi:10.15766/mep_2374 $-8265.10018$

6. Namba, J., Macauley, K., Zheng, A., Hutchins, S., Sweeney, K., Wallace, P., Garman, K., \& Awdishu, L. (2016). A large scale interprofessional simulation experience, module 2: What happens in Vegas does not stay in Vegas. MedEdPORTAL Publications, 12, 10331. doi:10.15766 /mep_2374-8265.10331

7. Agency for Healthcare Research and Quality. (2015). San Diego universities collaborate using TeamSTEPPS $^{\circledast}$ to boost professional education. Washington, DC: Agency for Healthcare Research and Quality, US Dept of Health and Human Services. URL: http://www.ahrq.gov /policymakers/case-studies/201516.html [January 2, 2017].

8. Chang, H. (2010). Autoethnography in health research - Growing Pains? Qualitative Health Research, 24(4), 443-451. doi:10.1177/1049732315627432

9. Clandinin, D.J., \& Connelly, F.M. (2000). Narrative inquiry: Experience and story in qualitative research. San Francisco, CA: Jossey-Bass.

10. Ryan, G.W., \& Bernard, H.R. (2003). Techniques to identify themes. Field Methods, 15(1), 85-109. doi:10.1177/1525822X02239569

11. Saldaña, J. (2009). The coding manual for qualitative researchers. Thousand Oaks, CA: Sage Publications. 


\section{JRIPE}

Interprofessional Education

Partnership

\section{Hurst, Macauley,}

Awdishu, Sweeney,

Hutchins, Namba,

Johnson, Wallace,

Garman, \& Zheng

\section{Journal of Research in Interprofessional Practice and Education}

12. Fook, J., D’Avray, L., Norrie, C., Psoinos, M., Lamb, B., \& Ross. F. (2013). Taking the long view: Exploring the development of interprofessional education. Journal of Interprofessional Care, 27(4), 286-291. doi:10.3109/13561820.2012.759911

13. Lamieux, N., Nicholas, C., \& Cohen, C. (2013). Making connections: Overcoming institutional barriers to interprofessional educational innovation through a faculty development program in simulation based education. Simulation in Healthcare: The Journal of the Society for Simulation in Healthcare, 8(6), 457-458. doi:10.1097/01.SIH.0000441459.81036.a6

14. Chung, H.O., Medina, D., \& Fox-Robichaud, A. (2016). Interprofessional sepsis education module: A pilot study. CJEM, 18(2), 143-145. doi:10.1017/cem.2015.42

15. Interprofessional Education Collaborative Expert Panel. (2011). Core competencies for interprofessional collaborative practice: Report of an expert panel. Washington, DC: Interprofessional Education Collaborative. URL: http://www.aacn.nche.edu/education-resources/ipecreport.pdf [January 2, 2017].

16. Canadian Interprofessional Health Collaborative. (2010). A national interprofessional competency framework. Vancouver, BC: Canadian Interprofessional Health Collaborative. URL: http://www.cihc.ca/files/CIHC_IPCompetencies_Feb1210r.pdf [January 2, 2017].

17. MacKenzie, D.E., Doucet, S., Nasser, S., Godden-Webster, A.L., Andrews, C., \& Kephart, G. (2014). Collaboration behind-the-scenes: Key to effective interprofessional education. Journal of Interprofessional Care, 28(4), 381-383. doi:10.3109/13561820.2014.890923

18. Buring, S.M., Bhushan, A., Grazeau, G., Conway, S., Hansen, L., \& Westberg, S. (2009). Keys to successful implementation of interprofessional education: Learning location, faculty development, and curricular themes. American Journal of Pharmaceutical Education, 73(4), 60. URL: https://www.ncbi.nlm.nih.gov/pmc/articles/PMC2720356 [January 2, 2017].

19. Buring, S.M., Bhushan, A., Broeseker, A., Conway, S., Duncan-Hewitt, W., Hansen, L., \& Westberg, S. (2009). Interprofessional education: Definition, student competencies, and guidelines for implementation. American Journal of Pharmaceutical Education, 73(4), 59. URL: https://www.ncbi.nlm.nih.gov/pmc/articles/PMC2720355 [January 2, 2017].

20. Headrick, L.A. (2000). Learning to improve complex systems of care. In Collaborative Education to Ensure Patient Safety (pp. 76-88). Washington, DC: HRSA/Bureau of Health Professions. URL: https://www.hrsa.gov/advisorycommittees/bhpradvisory/cogme/Publications /collaborativeedu.pdf [January 2, 2017].

21. Farrell, L., Bourgeois-Law, G., Regehr, G., \& Ajjawi, R. (2015). Autoethnography: Introducing "I" into medical education research. Medical Education, 49(10), 974-982. doi:10.1111/medu.12761
Journal of Research in Interprofessional Practice and Education 
Interprofessional Education

Partnership

Hurst, Macauley, Awdishu, Sweeney, Hutchins, Namba, Johnson, Wallace, Garman, \& Zheng

\section{Appendix A}

IPE interview guide

1. Think back to the beginning of this project and what initially attracted you to joining the collaborative. How has the work you've done together evolved since that time? Do you still feel the same level of commitment to one another and why?

2. Tell me a story about any time during the last three years of the project when you felt a level of cooperation between the different disciplines (nurses, pharma, med) that went beyond the anticipated or expected limits of the group goals. Who was involved? What did you value most about this situation?

3. Looking back over the last three years what qualities do you believe have most fostered enthusiasm, information sharing, and partnership toward common goals in this collaborative?

4. When you think about this collaborative partnership. What are the major themes of accomplishment you have achieved to this point? What do you hope to accomplish in the future?

5. What is the greatest return of investment for you as a professional looking back on the time and energy you have committed to this collaboration over three years? 